\title{
O domingo na TV aberta brasileira
}

\section{Claudia Erthal}

\section{Resumo:}

Um estudo sobre a grade de programação de domingo da TV aberta no Brasil com ênfase nas principais redes: Globo, Record e SBT, este artigo busca entender qual é o formato e qual é o discurso apresentado por essa grade e refletir de maneira crítica sobre as intenções que este discurso determina.

\section{Palavras Chave:}

Televisão, programação, grade, audiovisual, comunicação.

\begin{abstract}
:
An study on the shows that go on air in the Brazilian open TV on Sundays, focusing Globo, Record and SBT networks. This paper tries to understand what is the main structure of these programs and which speeches they produce, critically reflecting the intention that this speeches determine.
\end{abstract}

\section{Keywords:}

Television, shows, programs, audiovisual, communication.

Missa; culto; um programa rural; esportes; uma corrida de Fórmula 1; desenho animado; um programa de humor; outro de entretenimento durante a tarde; um show de prêmios; futebol; Silvio Santos; Gugu; Faustão; Fantástico; Domingo Espetacular; um reality show; um filme. É isso. Com alguma variação de canal para canal ou de rede para rede, essa tem sido a grade de programação do domingo na TV aberta brasileira nas últimas três décadas, as opções do domingo, responsável pelos anos de formação de gerações e, como conseqüência, pela formação de uma cultura.

É muito provável que a maioria dos cidadãos brasileiros com acesso a um aparelho de televisão e ao sinal de uma das três maiores redes de TV tenha esta experiência em comum: assistir televisão no domingo, reunir-se com a família para almoçar e a TV em frente a este eletrodoméstico tão importante ligado na Globo, Record ou SBT, ou em outra rede. Nem sempre tédio absoluto, nem sempre um prazer estonteante, mas sempre uma TV ligada no domingo em casa. A programação da TV aberta no domingo é elemento de uma cultura e ter a dimensão dessa influência é um dos assuntos que esta pesquisa pretende discutir.

O domingo na TV aberta é o que se pode entender como o dia das grandes redes nacionais, dos imensos "latifúndios" que se tornaram estas redes e que vêem se formando desde os anos 60 no Brasil. Hoje as grandes propriedades da comunicação estão divididas com a família Marinho com a Rede Globo, o Bispo Edir Macedo, com a Rede Record e de Silvio Santos, e com o SBT (Sistema Brasileiro de Televisão).

Domingo é um dia de domínio da televisão sobre a vida do brasileiro e é quando a família reunida em frente da TV tem acesso aos discursos e aos objetivos ideológicos na forma de entretenimento, informação e dramaturgia. Principalmente se entendermos dramaturgia na origem da palavra, como a 
condução de uma ação. Em geral o que vemos na TV aos domingos é o entretenimento dos programas de variedades e a informação das revistas eletrônicas que privilegiam o jornalismo.

Os telespectadores também estão expostos à linha de pensamento de cada uma das redes durante a semana, no entanto, esta pesquisa opta pelo domingo por considerar que neste dia - no que diz respeito ao telespectador - o núcleo familiar está reunido em frente à TV e - em relação ao meio de comunicação existe uma programação concentrada em vários formatos e gêneros que podem ser considerados a representação da grade de programação da emissora como um todo.

Este trabalho busca analisar a produção e a prática audiovisual dos conceitos e das linhas de pensamento que determinam a grade de programação dominical das três principais emissoras de TV aberta no Brasil. A intenção da pesquisa é que, ao analisar a grade, seja possível entender como as redes de TV aberta pensam a programação e montam estratégias para atrair o telespectador. A intenção é que ao verificar os programas exibidos neste dia e o conteúdo apresentado por eles, se torne clara a lógica do encadeamento destes produtos audiovisuais e qual pensamento(s) e discurso(s) é articulado por estas redes.

O projeto está no início. Os primeiros passos foram dados a partir das aulas, leituras e discussões da disciplina A Produção Audiovisual de Não-Ficção: Na Transversal da Imagem ministrada pela professora Dra. Marília da Silva Franco (ECA-USP), unidas à prática cotidiana desta autora como jornalista e editora de texto em emissora televisão aberta. Importante ressaltar aqui que o viver e fazer do audiovisual que estão presentes neste trabalho são também elementos de atenção para um curso focado no estudo de práticas audiovisuais e se apresentam como uma contribuição ao trabalho. A expectativa é também de que esta contribuição se amplie e possa gerar outras discussões e produções no futuro.

Leituras, discussões, conversas formais e, por vezes, informais sobre os assuntos aqui enfocados colaboraram para modificações e a evolução da idéia da pesquisa: um olhar crítico para o conjunto de pensamentos, fluxo e intenções exibidas pelos principais canais da TV aberta no domingo. E entenda-se aqui "principais" em importância de alcance populacional e de importância comercial. Afinal, a criação de uma grade de programação como a que conhecemos hoje é determinada pela venda dos espaços comerciais. O alcance populacional das redes gera uma maior venda destes espaços. Globo, SBT e Record são redes que possuem um número mais ampliado de anunciantes e que disputam palmo a palmo público os preços no mercado. O dia em que a emissora atinge um número muito grande de espectadores é também um dia de grande faturamento comercial.

Uma grade de programação é um quebra-cabeças, é a montagem de um pensamento, de uma idéia de TV, de comunicação, um fluxo, um conceito e, em longo prazo a influência na construção de uma cultura ou de parte dela. E esta pesquisa quer entender a idéia, desmontar a montagem da grade e olhar dentro dela.

Por que um programa vem depois do outro? Por que nessa ordem? De que maneira os produtos audiovisuais estão encadeados? Qual é a forma dessa ou daquela grade de programação? Existe autoria na grade de programação? Que discurso ela produz? O que a rede transmite ao exibir os programas neste dia da semana? Da mesma maneira que no roteiro de um telejornal as reportagens estão encadeadas e articuladas para atingirem um sentido, uma idéia geral. A grade e seus programas e produtos também obedecem uma montagem de pensamento que respeitam um conceito de emissora e de rede e por fim de ideologia de meio de comunicação que pertence a este ou àquele grupo econômico e/ou político.

O que vemos na programação é fruto da intenção deste grupo de transmitir uma idéia com o objetivo de atingir determinados fins. Por isso, a articulação dos produtos audiovisuais na grade de programação é um de interesse desta pesquisa, a maneira como esta grade está montada e o que esta montagem diz.

Este é um trabalho que está no início da pesquisa. O projeto teve uma ótima recepção por parte dos docentes e discentes do departamento com alguma contribuições valiosas como a dos professores doutores Eduardo Victorio Morettin, Rosana de Lima Soares e Esther Império Hamburger de que um autor fundamental a ser estudado é Raymond Williams em seu livro Television: Technology and Cultural Form. É um texto que ainda não havia sido incluído nesta bibliografia mas que, sem dúvida alguma, já 
passa a ser considerado, na busca do entendimento do fluxo gerado pela articulação entre os programas e produtos na programação televisa e de outras idéias que certamente vai gerar.

Outra contribuição ao trabalho é a possibilidade de restringir a pesquisa às redes Globo, Record e SBT, com a justificativa de que incluir Band e RedeTV! seria abrir demais o objeto de estudo. De qualquer maneira, a programação destas redes devem ser citadas na medida em que tiverem relevância para a pesquisa porque se tratam de redes nacionais com influência no assunto aqui abordado.

Esta pesquisa pretende traçar um histórico a respeito do domingo na TV: de como a programação do domingo se foi criada e construída. O dia que a família assiste TV reunida norteia o início da pesquisa que vai falar também das três redes de TV que marcaram e marcam o domingo do brasileiro e da diversificação da programação apresentada.

Para um histórico da criação da grade de programação é importante ler Campeão de Audiência, livro de Walter Clark e Gabriel Priolli. Clark foi uma das pessoas responsáveis por criar a TV brasileira como a conhecemos hoje, com a distribuição de programas e espaços comerciais e horários, ou seja, a grade de programação.

Alguns livros são fundamentais no trajeto da pesquisa: 50 Anos de TV no Brasil, de José Bonifácio de Oliveira Sobrinho, que durante décadas foi o homem por trás da Rede Globo de Televisão; Um país no ar - História da TV brasileira em três canais, de Alcir Henrique Costa com Inimá Ferreira Simões e Maria Rita Kehl, conta a saga das emissoras Tupi, Rio e Excelsior, que tiveram seus reinados até a metade dos anos 60 e formaram os padrões da programação da TV no Brasil; A TV aos 50 - Criticando a televisão brasileira no seu cinqüentenário, organizado por Eugênio Bucci, uma coletânea de artigos de especialistas e oferece uma visão do passado, presente e futuro da TV no país.

O recém-lançado A história da TV no Brasil traz artigos que discutem história e crítica da televisão brasileira ao longos dos seus sessenta anos de existência. Livros como o de Esther Hamburger, O Brasil antenado e da professora Ana Maria Ballogh, O discurso ficcional na TV, e Showrnalismo - A notícia como espetáculo, de José Arbex Jr., também estão entre as leituras que serão utilizadas para a pesquisa. Além, é claro, do texto TV aberta brasileira: economia política, cultura e comunicação, de Luiz Carlos Lopes, entre outros artigos e estudos, farão parte dos referenciais teóricos da pesquisa.

Neste momento a busca é por uma bibliografia que sirva como uma base sólida para a pesquisa. Teses, dissertações, livros, programas de TV, artigos, sítios na internet. Há um amplo material escrito sobre televisão, mas neste momento é raro o que trata da grade de programação e investiga a linha de pensamento deste veículo. Por isso, este trabalho se mostra como um material original e que conta com uma parcela de ineditismo de um assunto que requer uma dedicação acadêmica maior e que conta com espaço para ser aprofundado.

Serão necessárias leituras para definição de indústria cultural como na Dialética do wsclarecimento; leituras para entender a confecção e montagem de um discurso com em Viagem à irrealidade cotidiana, A ordem do discurso e $O$ terceiro sentido. Partindo do pressuposto de que a grade de programação produz e conduz uma certa dramaturgia televisiva, o livro Vida, o filme, de Neil Gabler, trata da espetacularização da vida e se coloca como uma leitura necessária.

Esses são apenas alguns títulos colocados para o início da pesquisa, que também deve contar com entrevistas como parte da metodologia de trabalho. Profissionais da área de comunicação e audiovisual serão entrevistados para discutir e elucidar o tema. São, em princípio, os diretores de programação das três redes em questão, além de outros profissionais com nomes a serem decididos posteriormente.

Compreender a grade de programação de uma emissora ou de uma rede é decifrar como pensa, qual sua identidade e que memória cria. O que está no ar, o que foi gravado e exibido é o que vira história, memória e cultura. Por isso, quais são as opções feitas ao se montar uma grade de programação? Tais opções nos mostram qual a história que escrita por essa grade.

A grade de programação é a impressão digital da rede de TV e de suas emissoras. Investigá-la, identificá-la e compreender como está definida é uma via possível para fornecer ferramentas que visam o entendimento de um universo crítico das práticas e articulações audiovisuais, e dos meios de comunicação com a ampla influência que têm sobre a sociedade brasileira. 


\section{Bibliografia:}

ADORNO, Theodor W. \& HORKHEIMER, Max. Dialética do esclarecimento. Rio de Janeiro: Jorge Zahar, 1985.

ARBEX, Jr., José. Showrnalismo. A notícia como espetáculo. São Paulo: Casa Amarela, 2003.

BALOGH, Anna Maria. O discurso ficcional na TV. São Paulo: Edusp, 2002.

BARTHES, Roland. O óbvio e o obtuso. Rio de Janeiro: Nova Fronteira, 1990.

BUCCI, Eugênio (org.). A TV aos 50 - Criticando a televisão brasileira no seu cinqüentenário. São Paulo: Fundação Perseu Abramo, 2000.

BUCCI, Eugênio. Brasil em tempo de TV. São Paulo: Boitempo, 1996.

CLARK, Walter \& PRIOLLI, Gabriel. Campeão de audiência. São Paulo: Best Seller, 1991.

COSTA, Alcir Henrique da; SIMÕES, Inima Ferreira; KEHL, Maria Rita. Um país no ar: história da TV brasileira em três canais. São Paulo: Brasiliense, 1986

ECO, Umberto. < irrealidade à>. Rio de Janeiro: Nova Fronteira, 1985.

EISENSTEIN, Sergei. A forma do filme. Rio de Janeiro: Jorge Zahar, 2004. . O sentido do filme. Rio de Janeiro: Jorge Zahar, 2004.

FOUCAULT, Michel. A ordem do discurso. São Paulo: Loyola, 1996. . Vigiar e punir. São Paulo: Loyola, 1996.

GABLER, Neil. Vida, o filme. São Paulo: Companhia das Letras, 1998.

HAMBURGER, Esther I. O Brasil antenado - A sociedade da telenovela. RJ: Jorge Zahar, 2005.

LOPES, Luiz Carlos. A TV aberta brasileira: economia política, cultura e comunicação. Disponível em: http://www.ucm.es/info/especulo/numero33/tvaberta.html.

MORIN, Edgar. "A alma do cinema". In: Xavier, Ismail (org.). A experiência do cinema. Rio de Janeiro: Graal, 2003.

NICHOLS, Bill. La representacíón de la realidad. Barcelona: Paidós, 1997.

OLIVEIRA SOBRINHO, José Bonifácio de. 50 anos de TV no Brasil. Rio de Janeiro: Globo, 2000.

PROPP, Vladimir I. Morfologia do conto maravilhoso. Rio de Janeiro: Forense Universitária, 1984.

RIBEIRO, Ana Paula Goulart; SACRAMENTO, Igor \& ROXO, Marco (orgs.). História da televisão no Brasil. São Paulo: Contexto, 2010.

SALLES GOMES, Paulo Emílio. Cinema: trajetórias do subdesenvolvimento. Rio de Janeiro: Paz e Terra, 1996.

SOUZA, José Carlos Aronchi de. Gêneros e formatos na televisão brasileira. São Paulo: Summus, 2004.

TAVOLARO, Douglas \& LEMOS, Christina. O bispo - A história revelada de Edir Macedo. São Paulo: Larousse, 2007.

WILLIAMS, Raymond. Television: technology and cultural form. London: Routledge, 2003.

\section{Notas:}

Trabalho apresentado na I Jornada Discente do Programa de Pós-Graduação em Meios e Processos Audiovisuais da Escola de Comunicações e Artes da Universidade de São Paulo (ECA-USP), realizada em novembro de 2010.

\section{Mini Currículo :}

Possui graduação em comunicação social (jornalismo) pela Universidade Federal de Santa Catarina e mestrado em filme e vídeo independente pela University of London. Atualmente é jornalista (TV RecordSP) e jornalista free lancer. Tem experiência nas áreas de comunicação e artes, com ênfase em cinema, TV e audiovisual. Atua como diretora, roteirista e editora de documentários e programas para televisão. 